\section{Interhemispheric transfer time for visual stimulus information varies as a function of the retinal locus of stimulation}

\author{
WALTER F. McKEEVER and KATHLEEN M. GILL \\ Bowling Green State University, Bowling Green, Ohio 43403
}

\begin{abstract}
Measurements of interhemispheric transfer time (ITT) were obtained from differences in vocal-report latencies for letter stimuli tachistoscopically channeled to the left and right hemispheres. This time was found to vary with the degree of stimulus lateralization (retinal location). Letters proejcted 1.6 deg from fixation into each lateral field yielded an average ITT of $41.4 \mathrm{msec}$. Stimuli projected $3.9 \mathrm{deg}$ from fixation yielded an average ITT of only $17 \mathrm{msec}$. The average ITT across retinal loci was 29.2 msec. The data strongly suggest that discrepant estimates of ITT, particularly from vocal reaction-time measures, reflect the differing retinal loci studied. Earlier, seemingly divergent, estimates of ITT were found to be quite consistent with those obtained for comparable loci in this experiment.
\end{abstract}

It has long been known that visual images falling on the right hemiretina project to the right cerebral hemisphere, while images falling on the left hemiretina project to the left hemisphere (Polyak, 1957). It is now similarly well established that, in nearly all right-handed persons, the left hemisphere is specialized for language expression (Penfield \& Roberts, 1959; Milner, Branch, \& Rasmussen, 1964; Sperry, 1968). Thus, stimuli channeled to the right hemisphere from the left visual field (LVF) must traverse an interhemispheric pathway in order to be reported, while no such transfer is necessary for the report of right visual field (RVF) stimuli. By channeling visual stimuli to one and then to the other hemisphere, one can measure any excess of report time for LVF over RVF stimuli, and this value can be regarded as a measure of interhemispheric transfer time (ITT). This general strategy for measuring ITT has been used recently by Filbey \& Gazzaniga (1969) and by Moscovitch \& Catlin (1970), the two experiments yielding average ITT values of 40 and $10.2 \mathrm{msec}$, respectively.

McKeever \& Huling (1971c), commenting on the findings of Filbey and Gazzaniga, pointed out that other estimates of ITT had been obtained over a long period of years and that these estimates, none of which was cited by Filbey and Gazzaniga, were consistently much shorter than the 40-msec value obtained by Filbey and Gazzaniga. Thus, Poffenberger (1912) obtained values on the order of 5 msec, Efron (1963) obtained values of 2-6 msec, and Jeeves (1969) obtained values of 2-3 msec for ITT in normal $\mathrm{Ss}$ and much longer ITT for persons with agenesis of the corpus callosum. McKeever and Huling suggested the need for an awareness of such divergent estimates and for the experimental explication of their bases.

Gazzaniga (1971), replying to the McKeever and Huling note, argued that Poffenberger's results were difficult to interpret, since Poffenberger's experimental strategy was based on the belief that the gross manual responses he employed could be initiated only from the contralateral cerebral hemisphere. There is now abundant evidence that such gross responses of either hand can, in fact, be initiated from either contralateral or ipsilateral hemispheres. Consequently, Gazzaniga's point in this regard was well taken. Still, the problem of accounting for the findings of Efron and of Jeeves remains. Efron's dependent measures were verbal reports as to the simultaneity of LVF and RVF light onsets, and Jeeves employed digital responses which, as Gazzaniga himself noted, appear to be exclusively under contralateral cerebral control. Furthermore, the 40vs 10-msec ITT estimates of Filbey and Gazzaniga and of Moscovitch and Catlin, respectively, which Gazzaniga (1971) cited as consistent evidence against the shorter ITT estimates of Efron, Jeeves, and Poffenberger, are actually quite discrepant in themselves.

One possible source of divergent ITT estimates which has received no attention is that different retinal stimulation loci were used in all of these experiments. Thus, the stimuli (dots) of Filbey and Gazzaniga were projected $1 \mathrm{deg}$ to the left and right of fixation; the Moscovitch and Catlin stimuli (letters) were projected $4.2 \mathrm{deg}$ from fixation; Efron's light stimuli were projected $26 \mathrm{deg}$ from fixation; and Jeeves's light stimuli were located $70 \mathrm{deg}$ from fixation. Interestingly, the magnitudes of ITT estimates derived from these experiments are inversely related to the degree of stimulus lateralization employed. The assumption in these experiments seems to have been that while absolute reaction times might increase as a function of increasing distance from the fovea, left-right differences (ITT) would be constant regardless of the degree of lateralization of the stimuli. 1

The hypothesis of the present experiment, on the other hand, was that recognition-report-time (RRT) gradients across the hemiretinae are asymmetrical, being most dissimilar near the center of vision and less dissimilar at more peripheral loci. An inevitable corollary was that the range of RRT in the LVF must be smaller than in the RVF.

To test these hypotheses, the present experiment derived estimates of ITT from $2 \mathrm{deg}$ of stimulus lateralization rather than from just 1 deg. The loci chosen closely approximated the positions used by Filbey and Gazzaniga, on the one hand, and by Moscovitch and Catlin, on the other. They also corresponded to the positions of the first and last letters of the four-letter word stimuli used in a series of studies demonstrating virtually universally greater RVF than LVF tachistoscopic word recognition among right-handed Ss (McKeever \& Huling, 1970a, b, $1971 \mathrm{a}, \mathrm{b}$; McKeever, 1971). An additional difference between this and previous experiments was the use of a procedure for the experimental control of visual fixation. ${ }^{2}$ Fixation control, absent from previous studies aimed at measuring ITT, is essential for real assurance that stimuli are channeled exclusively to the intended hemispheres and that comparable degrees of left-right stimulus lateralization are maintained.

\section{METHOD}

The Ss were 18 right-handed Bowling Green State University undergraduates with normal or corrected-to-normal visual acuity. Stimuli were the capital letters $A, H$, $M, O$, and $T$, chosen for their perfect symmetry about the vertical axis. Lettering was made from "press-on" lettering sheets (36-point, Futura Demi-Bold style). Letters appeared black on a white background. Lateral displacement of the letters corresponded to 1.6 and $3.9 \mathrm{deg}$ of lateral visual angle from fixation into each visual half-field (VHF), measured from fixation to the centers of the 
Table 1

Median RRT (Msec) for Each

Retinal Locus

\begin{tabular}{|c|c|c|c|c|}
\hline \multirow[b]{2}{*}{ Ss } & \multicolumn{2}{|c|}{ Left Visual Field } & \multicolumn{2}{|c|}{ Right Visual Field } \\
\hline & $\begin{array}{c}\text { 3.9-Deg } \\
\text { Locus }\end{array}$ & $\begin{array}{c}\text { 1.5-Deg } \\
\text { Locus }\end{array}$ & $\begin{array}{c}\text { 1.5-Deg } \\
\text { Locus }\end{array}$ & $\begin{array}{c}\text { 3.9-Deg } \\
\text { Locus }\end{array}$ \\
\hline 1 & 469 & 450 & 441 & 467 \\
\hline 2 & 595 & 548 & 535 & 507 \\
\hline 3 & 604 & 536 & 546 & 587 \\
\hline 4 & 683 & 677 & 696 & 663 \\
\hline 5 & 675 & 684 & 598 & 602 \\
\hline 6 & 476 & 450 & 426 & 449 \\
\hline 7 & 598 & 534 & 517 & 522 \\
\hline 8 & 464 & 468 & 475 & 510 \\
\hline 9 & 457 & 484 & 424 & 494 \\
\hline 10 & 575 & 561 & 489 & 503 \\
\hline 11 & 712 & 666 & 574 & 699 \\
\hline 12 & 642 & 606 & 547 & 654 \\
\hline 13 & 469 & 491 & 415 & 496 \\
\hline 14 & 629 & 536 & 482 & 669 \\
\hline 15 & 623 & 548 & 534 & 616 \\
\hline 16 & 713 & 762 & 701 & 710 \\
\hline 17 & 466 & 477 & 426 & 465 \\
\hline 18 & 736 & 704 & 611 & 667 \\
\hline Mean & 588.1 & 565.7 & 524.3 & 571.1 \\
\hline
\end{tabular}

Table 2

Excess of RRT (Msec) to LVF Over RVF Stimuli at Each Retinal Locus Studied and for Loci Combined Within VHFs

\begin{tabular}{rrrr}
\hline & \multicolumn{3}{c}{ Retinal Loci } \\
\cline { 2 - 4 } Ss & $\begin{array}{c}1.5-\text { Deg } \\
\text { Locus }\end{array}$ & $\begin{array}{c}\text { 3.6-Deg } \\
\text { Locus }\end{array}$ & $\begin{array}{c}\text { Combined } \\
\text { Loci }\end{array}$ \\
\hline 1 & 9 & 2 & 5.5 \\
2 & 13 & 88 & 50.5 \\
3 & -10 & 17 & 3.5 \\
4 & -19 & 20 & .5 \\
5 & 86 & 73 & 79.5 \\
6 & 24 & 27 & 25.5 \\
7 & 17 & 76 & 46.5 \\
8 & -7 & -46 & -26.5 \\
9 & 60 & -37 & 11.5 \\
10 & 72 & 72 & 72.0 \\
11 & 92 & 13 & 52.5 \\
12 & 59 & -12 & 23.5 \\
13 & 76 & -27 & 24.5 \\
14 & 54 & -40 & 1.0 \\
15 & 14 & 7 & 32.0 \\
16 & 61 & 3 & 26.0 \\
17 & 51 & 19 & 81.0 \\
18 & 93 & 17.00 & 29.19 \\
Mean & 41.39 & &
\end{tabular}

letters. Each of the 20 stimulus cards (five letters at each of four field positions) also had a smaller (18-point) fixation-control digit placed at midfield. The preexposure card was white, with a black circle at midfield. This circle designated the fixation point and was just large enough to be "filled" by the fixation control digit on each stimulus card as it was flashed.

Stimuli were presented in a Scientific Prototype tachistoscope (Model GB). A single exposure time of $50 \mathrm{msec}$ was used for all stimuli and all Ss. Luminances of the preexposure and exposure fields, measured with a Pritchard "Spectra" photometer, were 13.5 and $11.5 \mathrm{fL}$, respectively.

Each $S$ received a total of 100 recognition-report trials, 25 trials at each field position. Stimulus position order was randomized within blocks of 20 trials. Six totally unique position orders of the 100 trials were employed, each order being administered to three different Ss.

The Ss were instructed in the importance of fixating within the circle and given two trials in which single digits (without letters) were exposed for $25 \mathrm{msec}$. This established familiarity with the proper fixation procedure and ensured that the $S$ s possessed sufficient acuity to perform the task. Ss were then told that the experimental task would be to identify, as quickly as possible, the single letters that would appear, at unpredictable locations, on each trial.

The onset of the tachistoscopic exposure started a Hunter Klockounter timer, and Ss' vocal reports of the letters exposed activated a Scientific Prototype audio-detection relay, which stopped the timer.
Recognition-report times (RRTs) were recorded to the nearest millisecond. Following the recognition report of the exposed letter, Ss were asked what number had appeared in the fixation circle. Failure to correctly identify the fixation control number resulted in a discarded trial, and $S$ s were informed of any such errors. These error trials were reinserted at the end of the trial block in which they occurred. The need to repeat trials because of failure to identify the fixation control numbers or because of errors in reporting the stimulus letters were very infrequent after the first block of trials, because Ss learned that the task could be accomplished successfully only by fixating the proper point.

At the completion of each block of trials, Ss were given a 1-min "rest," during which they were informed of their slowest and fastest RRTs during the block. They were always told prior to resuming the task that they could probably achieve faster RRTs in the up-coming block. This procedure was designed to motivate good performance and to reduce RRT variability.

Following the experimental task, information was secured from each $S$ as to his ocular sighting dominance and as to whether he had any left-handed parents or siblings.

\section{RESULTS}

Median RRTs of the $18 \mathrm{Ss}$ to each of the four stimulus positions, as well as the group means for each locus, are shown in Table 1. A Treatments by Ss analysis of variance applied to these scores yielded a significant treatments (loci) effect ( $F=12.6, d f=3 / 51$, $\mathrm{p}<.001$ ), allowing rejection of the overall null hypothesis. The significances of differences between individual means were subsequently assessed by t-ratio tests for correlated means, interpreted with respect to one tail of the distribution.

Table 2 shows VHF differences in RRT between the 1.6- and 3.9-deg loci and RRT differences for the combined 1.6- and 3.9-deg loci between VHFs. The RRT for the 1.6-deg locus averaged 41.4 msec faster for the RVF than for the LVF. This mean difference was significant beyond the .0005 level $(t=4.57, \mathrm{df}=17)$. The number of Ss showing faster RVF RRTs at the 1.6-deg locus (15) was significantly larger than the number showing faster LVF RRTs (3) by the binomial test $(p<.004)$. The RRTs for the 3.9-deg locus averaged 17.0 msec faster for the RVF than for the LVF, but this difference was short of significance $(t=1.68, d f=17$, $p<.10)$. The number of Ss showing faster RVF RRTs at the 3.9-deg position (13) was significantly greater than the number showing faster LVF RRTs at this position (5) by the binomial test $(\mathbf{p}<.05)$. The overall RRT advantage for the RVF (29.2 msec) was significant $(t=4.21$, df $=17, p<.0005)$. Seventeen of the $18 \mathrm{Ss}$ had shorter RRT for the combined loci of the RVF than of the LVF ( $p<.001$ ).

Inspection of the mean RRT data in Table 1 will dso show that, as expected, RRTs increased as a function of lateral distance from fixation. In the LVF, RRTs averaged 22.4 msec faster at the $1.6-\mathrm{deg}$ than at the 3.9-deg locus $(t=2.45, d f=17$, $p<.025$ ). In the RVF, RRTs averaged $46.8 \mathrm{msec}$ faster at the 1.6-deg than at the 3.9-deg locus $(t=3.61, d f=17$, 
$\mathrm{p}<.005)$. The difference in the degree to which the 3.9-deg-loci RRTs exceeded the 1.6-deg-loci RRTs in the two VHF (24.4 msec) was also significant $(t=2.00, \mathrm{df}=17, \mathrm{p}<.05)$.

Only two Ss (Ss 6 and 18) were left-eyed, and their performance was similar to that of the average $S$. Five Ss (Ss 6, 8, 11, 14, and 15) had a family history of left-handedness, as defined by familial sinistrality of a parent or sibling. These Ss had a mean RVF RRT only $13.8 \mathrm{msec}$ faster than for the LVF. The 13 Ss without a history of familial left-handedness had a mean RVF RRT 35.1 msec faster than for the LVF.

\section{DISCUSSION}

The results showed that RRTs for stimuli transmitted directly to the left hemisphere were significantly shorter than for stimuli transmitted to the left hemisphere via an interhemispheric pathway. The magnitude of this direct vs interhemispheric RRT difference (ITT) varied with the degree of stimulus lateralization employed. This central finding duplicates the essential results of a cruder pilot study with 12 Ss (McKeever \& Gill, 1971) and demonstrates the fallacy of speaking of "the" ITT. ${ }^{3}$ Stimulation loci nearer the fovea centralis yielded a large and clearly significant ITT, while more peripheral stimuli yielded a smaller and marginally significant ITT. This lends credibility to the general notion suggested in the introductory section of this paper, namely, that the very small ITTs obtained in the Jeeves (1969) and Efron (1963) experiments may reflect the wide lateral displacements of the stimuli employed. Experiments utilizing such wide displacements of stimuli, but otherwise identical in methodology, would provide more definitive evidence with regard to the generality of this hypothesis.

The results also suggest that, when locus of retinal stimulation is taken into account, a surprising degree of agreement obtains between estimates of ITT derived from vocal reaction time measures. Filbey and Gazzaniga stimulated a point $1 \mathrm{deg}$ off fixation, while Moscovitch and Catlin stimulated a point $4 \mathrm{deg}$ off fixation. The 1.6- and 3.9-deg loci of the present experiment approximate closely the loci of the Filbey and Gazzaniga and of the Moscovitch and Catlin experiments, particularly when one considers that our stimuli extended from .16 to $.28 \mathrm{deg}$, depending on the width of the particular letter, to either side of the 1.6- and 3.9-deg centers. The ITT values obtained by Filbey and
Gazzaniga ranged from 33 to $46 \mathrm{msec}$, the midpoint of this range being virtually identical to the 41.4-msec ITT we measured at the 1.6-deg locus. The ITT estimate of 17 msec obtained for the $3.9 \mathrm{deg}$ locus is also reasonably close to the 10.2-msec ITT obtained by Moscovitch and Catlin. These various estimates, then, appear consistent when retinal locus of stimulation is taken into account. This degree of consistency also suggests that the experimental instruction to fixate the proper point in the earlier studies was sufficient to secure fairly stable fixation from Ss.

Present results also showed a greater temporal separation of the 1.6- and 3.9-deg loci within the RVF than within the LVF. As mentioned earlier, these loci correspond to those stimulated by the first and last letters of the four-letter words used in a series of experiments demonstrating marked R VF word-recognition superiority (McKeever \& Huling, 1970a, b, 1971a, b; McKeever, 1971). This "compression" of LVF RRTs relative to the RVF could indicate a lesser total processing time availability of LVF words which could produce, or at least contribute to, the RVF word-recognition superiority. It also seems reasonable to suspect that this temporal compression of LVF stimuli may underlie the VHF differences in masking effects recently demonstrated for sequentially presented letters (McKeever \& Gill, 1971; McKeever \& Suberi, 1971). 4

The small number of Ss with a familial history of left-handedness precludes statistical evaluation of the significance of their generally smaller ITTs. The result is suggestive, however. Hines \& Satz (1971) have recently reported differences in the extent of RVF recognition superiority for briefly exposed digit series in right-handers with and without such indication of familial left-handedness. Finally, that differences in ocular sighting dominance appeared unrelated to obtained ITT magnitudes is consistent with the observation of Moscovitch \& Catlin (1970).

\section{REFERENCES}

EFRON, R. The effect of handedness on the perception of simultaneity and temporal order. Brain, 1963, 86, 285-294.

FILBEY, R. A., \& GAZZANIGA, M. S. Splitting the normal brain with reaction time. Psychonomic Science, 1969, 17, 335-336.

GAZZANIGA, M. S. Reply to McKeever and Huling. Psychonomic Science, 1971, 22, 223-224.
HINES, D. \& SATZ, P. Superiority of right visual half-fields in right-handers for recall of digits presented at varying rates. Neuro psy chologia, 1971, 9, 21-25.

JEEVES. M. A. A comparison of interhemispheric transmission times in acallosals and normals. Psychonomic Science, 1969, 16, 245-246.

MCKEEVER, W. F. Lateral word recognition: Effects of unilateral and bilateral presentation, asynchrony of bilateral presentation, and forced order of report. Quarterly Journal of Experimental Psychology, 1971, in press.

MCKEEVER, W, F., \& GILL, K. M. Visual half-field differences in masking effects for sequential letter stimuli in the right and left-handed. Neuropsychologia, in press.

MCKEEVER, W. F. \& HULING, M. D. Left cerebral hemisphere superiority in tachistoscopic word recognition performances. Perceptual \& Motor Skills, 1970a, 30, 763-766.

MCKEEVER, W, F \& HULING, M D. Lateral dominance in tachistoscopic word recognitions of children at two levels of ability. Quarterly Journal of Experimental Psychology, 1970b, 22, 600-604.

MCKEEVER, W. F., \& HULING, M. D. Lateral dominance in tachistoscopic word recognition performances obtained with simultaneous bilateral report. Neuropsychologia, 1971a, 9, 15-20.

MCKEEVER, W. F., \& HULING, M. D. Bilateral tachistoscopic word recognition as a function of hemisphere stimulated and interhemispheric transfer time. Neuropsychologia, $1971 \mathrm{~b}, 9,281-288$.

MCKEEVER, W. F., \& HULING, M. D. A note on Filbey and Gazzaniga's "Splitting the brain with reaction time." Psychonomic Science, 1971c, 22, 222.

MILNER, B., BRANCH, C., \& RASMUSSEN, T. Observations on cerebral dominance. In A.V. S. de Reuck and M. O'Connor (Eds.), Ciba symposium on disorders of language. London: J. \& A. Churchill, 1964.

MOSCOVITCH, M., \& CATLIN, J. Interhemispheric transmission of information: Measurement in normal man. Psychonomic Science, 1970, 18, 211-213.

PENFIELD, W., \& ROBERTS, L. Speech and brain mechanisms. Princeton: Princeton University Press, 1959.

POFFENBERGER, A. $T$. Reaction time to retinal stimulation with special reference to the time lost in conduction through nerve centers. Archives of Psychology (New Yodk), 1912, No 23.

POLYAK, S. The vertebrate visual system. Chicago: University of Chicago Press. 1957.

SPERRY, R. W, Mental unity following surgical disconnection of the cerebral hemispheres. The Harvey Lectures, Series 62. New Yodk: Academic Press, 1968 .

1. This reflects the view that ITT is strictly a function of the time required to cross the corpus callosum. Actually, intrahemispheric delays in pre- or postinterhemispheric transfer may account for most of ITT values.

2. This technique was initially suggested by Sperry (1968).

3. McKeever, W. F., \& Gill, K. M. Interbemispheric transmission time for visual stimulus information as a function of the retinal locus of stimulation. Unpublished manuscript.

4. McKeever, W. F., \& Suberi, M. Differential visual half-field masking functions and interhemispheric processing delay. In preparation. 